\title{
Biological control of strawberry crown rot, root rot and grey mould by the beneficial fungus Aureobasidium pullulans
}

\author{
Mudassir Iqbal (1) - Maha Jamshaid (1) - Muhammad Awais Zahid (1D) \\ Erik Andreasson $(1) \cdot$ Ramesh R. Vetukuri 1 - Johan A. Stenberg $($ )
}

Received: 11 November 2020/Accepted: 1 March 2021 / Published online: 18 March 2021

(C) The Author(s) 2021

\begin{abstract}
Utilization of biocontrol agents is a sustainable approach to reduce plant diseases caused by fungal pathogens. In the present study, we tested the effect of the candidate biocontrol fungus Aureobasidium pullulans (De Bary) G. Armaud on strawberry under in vitro and in vivo conditions to control crown rot, root rot and grey mould caused by Phytophthora cactorum (Lebert and Cohn) and Botrytis cinerea Pers, respectively. A dual plate confrontation assay showed that mycelial growth of $P$. cactorum and $B$. cinerea was reduced by $33-48 \%$ when challenged by $A$. pullulans as compared with control treatments. Likewise, detached leaf and fruit assays showed that $A$. pullulans significantly reduced necrotic lesion size on
\end{abstract}

Handling Editor: Jane Debode

Mudassir Iqbal and Maha Jamshaid equally contributed to this work.

Supplementary Information The online version contains supplementary material available at https://doi.org/10.1007/ s10526-021-10083-w.

M. Iqbal ( $₫) \cdot$ M. Jamshaid · M. A. Zahid ·

E. Andreasson · J. A. Stenberg

Department of Plant Protection Biology, Swedish

University of Agricultural Sciences, Alnarp, Sweden

e-mail: mudassir.iqbal@slu.se

R. R. Vetukuri

Department of Plant Breeding, Swedish University of

Agricultural Sciences, Alnarp, Sweden leaves and disease severity on fruits caused by $P$. cactorum and $B$. cinerea. In addition, greenhouse experiments with whole plants revealed enhanced biocontrol efficacy against root rot and grey mould when treated with $A$. pullulans either in combination with the pathogen or pre-treated with A. pullulans followed by inoculation of the pathogens. Our results demonstrate that $A$. pullulans is an effective biocontrol agent to control strawberry diseases caused by fungal pathogens and can be an effective alternative to chemical-based fungicides.

Keywords Aureobasidium pullulans $\cdot$ Biological control - Botrytis cinerea $\cdot$ Fragaria $\times$ ananassa. Garden strawberry $\cdot$ Phytophthora cactorum

\section{Introduction}

Strawberry (Fragaria $\times$ ananassa Duch.) is one of the most fungicide-dependent crops, being highly susceptible to many pathogens (Garrido et al. 2011). This study investigates the potential to control two of the most detrimental strawberry pathogens using the candidate biocontrol agent Aureobasidium pullulans.

The hemibiotrophic oomycete Phytophthora cactorum (Lebert and Cohn) Schröeter, is a destructive pathogen that causes crown and root rot disease in strawberry (Ellis et al. 1998; Golzar et al. 2007; Nellist 
et al. 2019; Porras et al. 2007; Stensvand et al. 1999). Characteristic symptoms include wilting of plants and brown necrosis of vascular tissues of the crown, sometimes leading to complete yield loss. P. cactorum forms sexual oospores, which are a primary source of inoculum that remains persistent in the soil for several years, making management difficult (Nellist et al. 2019). When conditions are favourable, oospores germinate to produce sporangia which release more oospores, these give rise to sporangia that produce zoospores. Zoospores are the asexual motile stage and they are chemotactically attracted to roots, where they attach to the surface and penetrate the root epidermis. Subsequently, they start developing haustoria to acquire nutrients from the root for their growth and sporulation (Nellist et al. 2019).

The other devastating strawberry pathogen considered herein is the ascomycete necrotrophic fungus Botrytis cinerea Pers (perfect stage Botryotinia fuckeliana) which is the causative agent of grey mould on strawberry fruits (Petrasch et al. 2019). Grey mould is prevalent on all continents, mainly in cool, temperate, and warm-temperate zones (Jarvis 1977). The pathogen acts as a saprophyte in the absence of hosts and remains dormant under unfavourable conditions. Conidia from adjacent infected plants can be dispersed via the air and by water splashes, which facilitate primary infection, entering the plants through any injury or natural opening. Often an attack of the bottom of the receptacle occurs and the mycelium remains quiescent until ripening of fruits. Penetration can take place through open flowers (Bristow et al. 1986). Once environmental conditions become favourable, i.e., long periods of high humidity with temperatures around $25^{\circ} \mathrm{C}$, the pathogen starts causing rotting of flowers, fruits and leaves. If favourable conditions continue, B. cinerea keeps on sporulating, and this becomes the source of secondary inoculum. The infection severity of $B$. cinerea on strawberry plants is greatly increased under wet conditions and more than $80 \%$ of the flowers and fruit may die if fungicides are not applied in adequate time (Ries 1995).

Until now, the major approach to disease control in strawberry production has relied upon the use of synthetic fungicides. However, fungicide applications bring a range of issues such as accumulation of toxic residue on the fruits, development of resistance in the targeted pathogens, withdrawal of the chemical products from the market, and negative impact on the environment and human consumers (Dianez et al. 2002; Iqbal et al. 2019; Myresiotis et al. 2007; Rabølle et al. 2006; Yourman and Jeffers 1999). Moreover, application of fungicides in the flowering stage may reduce pollen viability and consequently hamper fruit formation (Kovach et al. 2000). In addition, application of fungicides is not allowed in organic production (Iqbal et al. 2018), hence the necessity for the development and implementation of alternative control strategies.

The yeast like fungus Aureobasidium pullulans (De Bary) G. Armaud is a candidate biocontrol agent and is naturally present in the phyllosphere and carposphere of several fruits and vegetables, and accompanied with the endophyte population of various species of plant (Bozoudi and Tsaltas 2018). A. pullulans has potential to control fruit and vegetable diseases caused by fungal pathogens primarily during the post-harvest phase and can be used either alone or in combination with other sustainable physical methods (Di Francesco et al. 2018, 2020; Di Francesco and Mari 2014; Zhang et al. 2010). Certain A. pullulans strains have shown the ability to control fungal pathogens involved in causing post-harvest diseases, such as $B$. cinerea in grapes, Monilinia spp. in stone fruits and Penicillium expansum in apple (Di Francesco et al. 2018, 2020; Mari et al. 2012; Parafati et al. 2015, 2017). Many different biocontrol mechanisms have been described for A. pullulans including antibiosis through the production of antifungal compounds and enzymes (Parafati et al. 2015; Zhang et al. 2010), competition for space and nutrients (Di Francesco et al. 2018; Janisiewicz et al. 2000; Klein and Kupper 2018), mycoparasitism (Klein and Kupper 2018) and the induction of plant defence resistance (Di Francesco et al. 2017; Madhupani and Adikaram 2017).

To date, no studies have been conducted to investigate the biocontrol potential of A. pullulans for countering crown and root rot in strawberry. Therefore, this study was designed to explore the biocontrol efficacy of four different strains of $A$. pullulans against crown rot, root rot and grey mould on strawberry. We hypothesize that (1) A. pullulans can antagonize and inhibit the growth of $P$. cactorum and B. cinerea, (2) the antagonistic potential varies between different $A$. pullulans strains, and (3) application of $A$. pullulans leads to successful biocontrol of root rot and grey mould in strawberry. The results of 
this study suggest that all the tested A. pullulans strains significantly inhibited the mycelial growth of $P$. cactorum and B. cinerea. Additionally, either preapplication of A. pullulans or simultaneous application with the respective pathogens enhanced the protection against root rot and grey mould under greenhouse conditions. These results show that augmentation biological control using A. pullulans has great potential to combat the pathogens, and thus reduce fungicide dependency in strawberry production.

\section{Materials and methods}

Plant material

Plantlets of two different strawberry (Fragaria $\times$ ananassa) cultivars, Ostara and Honeoye, were obtained from Plantagen (Lund and Malmö, Sweden). The plants were grown in a greenhouse for ten weeks before being used in the experiment. Strawberry fruits ( $c v$. Honeoye) were collected from Borgeby Jordgubbar farm, Bjärred, Sweden.

Fungal/oomycete strains and maintenance conditions

A. pullulans strains (Table 1) AP-30044, AP-30273, AP-53383 and AP-SLU6, P. cactorum strain RV4, and $B$. cinerea strain $\mathrm{B} 05.10$ were maintained on potato dextrose agar (PDA) medium (Oxoid; Basingstoke,
Hampshire, England) at $25{ }^{\circ} \mathrm{C}$ under dark conditions. All fungal and oomycete strains were revived from stock culture preserved in $20 \%$ (wt/vol) glycerol at $-80{ }^{\circ} \mathrm{C}$.

Inoculum preparation

The cultures of all A. pullulans strains, $P$. cactorum and $B$. cinerea were maintained on PDA plates at $25{ }^{\circ} \mathrm{C}$ for four weeks under dark conditions. The conidia produced by the A pullulans strains and $B$. cinerea were harvested by adding 6-8 $\mathrm{ml}$ of sterile water to the fungal culture, followed by scraping the surface of the mycelium with a spreader. The zoospores produced by $P$. cactorum were obtained following the protocol of Toljamo et al. (2016). The concentrations of conidia and zoospores were determined using a haemocytometer (Hausser Scientific, Horsham, PA) under a light microscope (Laborlux12 Leitz, Germany).

In vitro antagonistic assays

\section{Fungal confrontation assay}

The in vitro antagonistic ability of $A$. pullulans strains against $P$. cactorum and $B$. cinere $a$ was determined by performing a dual-plate confrontation assay. A $9 \mathrm{~cm}$ PDA plate was inoculated with a $15 \mathrm{~mm}$ diameter mycelial agar plug of an A. pullulans strain on one side of the plate. After seven days of incubation at $25^{\circ} \mathrm{C}$,

Table 1 List of Aureobasidium pullulans strains used in this study including their origin

\begin{tabular}{|c|c|c|c|c|}
\hline Strain ID & Other ID & Provided by & Origin & Isolated from \\
\hline AP-30044 & $\begin{array}{l}\text { CCUG-30044 } \\
\text { CBS } 123.37\end{array}$ & $\mathrm{CCUG}^{\mathrm{a}}$ & $\begin{array}{l}\text { CBS }^{\text {b }} \text {, Baarn, The Netherlands } \\
\text { 20-04-1992 }\end{array}$ & Unknown \\
\hline AP-30273 & $\begin{array}{l}\text { CCUG-30273 } \\
\text { IHEM } 5520\end{array}$ & $\mathrm{CCUG}^{\mathrm{a}}$ & $\begin{array}{l}\text { IHEM }^{\mathrm{c}} \text {, Brussels, Belgium } \\
19-06-1992\end{array}$ & Environment of an asthmatic patient \\
\hline AP-53383 & $\begin{array}{l}\text { CCUG-53383 } \\
\text { A } 2006322 / 3\end{array}$ & $\mathrm{CCUG}^{\mathrm{a}}$ & $\begin{array}{l}\text { Anonymous, Sweden } \\
05-09-2006\end{array}$ & Water, RO quality, industry \\
\hline AP-SLU6 & - & $\mathrm{SLU}^{\mathrm{d}}$ & SLU $^{\mathrm{d}}$, Alnarp, Sweden & Wild woodland strawberry (Fragaria vesca) \\
\hline
\end{tabular}


an agar plug of $B$. cinerea was inoculated at an equal distance on the opposite side of the plate to compensate for the growth difference. P. cactorum, however, was inoculated on the same day as A. pullulans and mycelial growth was measured daily for up to five days post-inoculation (DPI). The growth rates of $P$. cactorum and $B$. cinerea were compared with the control treatment in which the pathogenic fungi remained unchallenged by the A. pullulans strain. The assay was performed on six biological replicates. The experiment was performed in duplicate.

\section{Detached leaf assay against $P$. cactorum}

As all A. pullulans strains displayed similar patterns in the confrontation assay, we focused all consecutive experiments on one strain (AP-SLU6) only. In addition to being a root pathogen, $P$. cactorum also causes crown rot disease, which affects both crowns and leaves. Therefore, strawberry leaves ( $c v$. Ostara) were detached and injuries were inflicted using a sterile razor blade by gently scraping the surface of the leaves. The conidial concentration of the A. pullulans strain AP-SLU6 and $P$. cactorum was maintained at $1.5 \times 10^{5}$ conidia or zoospores $\mathrm{ml}^{-1}$ followed by inoculation of $20 \mu \mathrm{l}$ to the injured surface of each leaf and then incubation at $22{ }^{\circ} \mathrm{C}, 90 \% \mathrm{RH}$ for one week. The lesion diameter was measured at a resolution of seven DPI using ImageJ software (version 1.52p). Five treatments were included: (1) leaves + water only, (2) leaves $+P$. cactorum $(P c)$ only, (3) leaves + APSLU6 only, (4) leaves $+P c+$ SLU6 (combined application), (5) leaves $+P c+$ AP-SLU6 (pre-application). In the fourth treatment, a mixture of the biocontrol and the pathogenic fungi was applied in a single delivery, while the fifth treatment involved pretreated with A. pullulans strain AP-SLU6 followed by inoculation of $P$. cactorum after $24 \mathrm{~h}$ of incubation. The assay was performed on six biological replicates of each treatment. The experiments were performed in duplicate.

\section{Trypan blue staining of leaves}

The leaf tissues were washed with tap water for $10 \mathrm{~min}$, then dipped in $70 \%$ ethanol for $2 \mathrm{~s}$ for disinfection. Subsequently, surface sterilization was performed with sodium hypochlorite (NaCLO) for 5 min, followed by washing 3-4 times with distilled water, as described previously (Munir et al. 2015). Thereafter, trypan blue was used to stain infected leaf tissue. The protocol was adapted from van Wees (2008). In brief, samples were submerged in trypan blue solution $\left(1: 1\right.$ mixture $(\mathrm{v} / \mathrm{v}), 2.5 \mathrm{mg} \mathrm{ml}^{-1}$ trypan blue, $25 \%$ v/v lactic acid, $25 \%$ glycerol, $25 \%$ phenol, and water), boiled for $5 \mathrm{~min}$, and incubated overnight at room temperature to stain. Leaves were de-stained with chloral hydrate solution ( $250 \mathrm{~g}$ in $100 \mathrm{ml} \mathrm{H}_{2} \mathrm{O}$ ) and left in the solution for two days. The chloral hydrate solution was replaced with $50 \%$ glycerol for the storage of samples. Images were acquired using an Epson Perfection V750 pro scanner.

\section{Detached fruit assay against B. cinerea}

Green strawberry fruits ( $c v$. Honeoye) were harvested from the field, brought to the laboratory and then surface sterilized as described above. The fruits were injured by scraping with a sterile razor blade across the surface close to their neck. The conidial concentration of A. pullulans strain AP-SLU6 and B. cinerea was maintained at $1.5 \times 10^{5}$ conidia $\mathrm{ml}^{-1}$, and $15 \mu \mathrm{l}$ was inoculated onto the injured neck of each fruit before being sealed in a plastic tray, incubated at $22{ }^{\circ} \mathrm{C}$ and maintained at $70 \% \mathrm{RH}$ for ten days. Four treatments were included: (1) fruits $+B$. cinerea $(B c)$ only, (2) fruits + AP-SLU6 only, (3) fruits $+B c+$ AP-SLU6 (combined application), (4) fruits $+B c+$ AP-SLU6 (pre-application). In the third treatment, a mixture of the biocontrol and the pathogenic fungi was applied in a single delivery, while treatment four involved pretreated with A. pullulans AP-SLU6, followed by inoculation of $B$. cinerea after $48 \mathrm{~h}$ of incubation. The disease severity was scored at a resolution of 10 DPI as described previously (Adikaram et al. 2002). The assay was performed using ten biological replicates of each treatment. The experiments were performed twice. The following scale was used: 0: no fungal growth, 1: fungal growth only on the margin of the lesion, 2: even but slight fungal growth all over, and 3: dense fungal growth all over.

In vivo biocontrol assays

\section{Biocontrol of root rot disease}

Root rot assays on strawberry ( $c v$. Ostara) plants were performed in a greenhouse, using a complete 
randomized experimental design. The strawberry plants were removed from their plastic pots, whereafter the roots were washed with tap water, and subsequently placed in glass jars for $3 \mathrm{~h}$, these were filled with approximately $150 \mathrm{ml}$ of $P$. cactorum zoospore suspension contained with $1.5 \times 10^{5}$ zoospores $\mathrm{ml}^{-1}$. The assay was performed using five treatments: (1) plant + water only, (2) plant $+P c$ only, (3) plant + AP-SLU6 only, (4) plant $+P c+$ AP-SLU6 (combined application), (5) plant $+P c+$ AP-SLU6 (pre-application). Six biological replicates were used for each treatment. In the combined application, a mixture of the biocontrol and the pathogenic fungi was applied in a single delivery in the same jar, while the pre-treatment involved application of SLU6 followed by inoculation of P. cactorum after $24 \mathrm{~h}$ of incubation. Afterwards, the roots were removed from the jars and placed in plastic pots that were filled with $150 \mathrm{~g}$ of soil and incubated in a greenhouse at $23 \pm 2{ }^{\circ} \mathrm{C}$ for four weeks. The disease scoring was performed by measuring the infected area of the roots using the following scale: 1:0-20\%, $2: 21-40 \%, 3: 41-60 \%, 4: 61-80 \%, 5: 61-80 \%$ and 6:81-100\%.

\section{Biocontrol of grey mould disease}

A grey mould assay on strawberry ( $c v$. Honeoye) plants was performed in a greenhouse using a complete randomized experimental design. Plastic pots were filled with $150 \mathrm{~g}$ of soil and planted with strawberry plants, then maintained at 20 to $22{ }^{\circ} \mathrm{C}$. The same conidial concentration was used as in the detached fruit assay against $B$. cinerea. The prepared formulation of $A$. pullulans strain AP-SLU6 was sprayed on flowers and fruits every seven days for the three weeks of the experiment, while $B$. cinerea was applied once. Five treatments were included in the assay: (1) plant + water only, (2) plant $+B c$, (3) plant + AP-SLU6 only, (4) plant $+B c+$ AP-SLU6 (combined application), (5) plant $+B c+$ AP-SLU6 (pre-application). Six biological replicates were used for each treatment. Pre-treatment was performed with AP-SLU6 followed by inoculation of $B$. cinerea after $48 \mathrm{~h}$ of incubation, while in the combined application, a mixture of the biocontrol and the pathogenic fungi was applied in a single delivery. The inoculation was performed using a hand sprayer. After four weeks, the disease severity was scored by measuring the density of mycelial growth as described previously (Adikaram et al. 2002). In short, 0: no fungal growth, 1: fungal growth only on the margin of the lesion, 2: even but slight fungal growth all over, and 3: dense fungal growth all over.

Statistical analysis

Data on growth rates and lesion size were analysed using ANOVA in Minitab 18.1 (Minitab Inc., State College, PA, USA). Subsequent pairwise comparisons were carried out using Fisher's least significant difference at $95 \%$ significance level. Disease score data were not normally distributed and global comparisons were thus analysed using non-parametric Kruskal-Wallis tests. Pairwise comparisons were made using Dunn's test with Bonferroni correction for multiple comparisons. The mycelial growth of the $P$. cactorum and $B$. cinerea during the confrontation assay, lesion size on the leaves and severity of grey mould disease during in vitro or in vivo assays were used as dependent variables.

\section{Results}

In vitro antagonism assay against fungal pathogens

The antagonistic ability of the four A. pullulans strains was tested against $P$. cactorum and $B$. cinerea in a dual-plate confrontation assay. $P$. cactorum and $B$. cinerea showed significantly reduced growth rates during confrontation with all $A$. pullulans strains compared with their growth rates when grown alone (control) at a resolution of three and five DPI respectively (Fig. 1). P. cactorum showed a significantly reduced growth rate $\left(\mathrm{F}_{4,25}=8.28 ; p<0.001\right)$ when challenged with $A$. pullulans strains compared with the control treatment at five DPI (Fig. 1a). The highest reduction $(42-44 \%)$ in the growth of $P$. cactorum was observed in the presence of AP-30273 and AP-SLU6 followed by AP-53383 and AP-30044, where mycelial growth was reduced by as much as 28-30\% compared with the control treatment (Fig. 1a). Similarly, the AP-30044 strain significantly $\left(\mathrm{F}_{4,25}=26.75 ; p<0.001\right)$ reduced the growth $(48 \%)$ of B. cinerea followed by AP-53383 (44\%) while AP30273 and AP-SLU6 reduced the growth of $B$. cinerea by $26-33 \%$ compared with the control treatment 


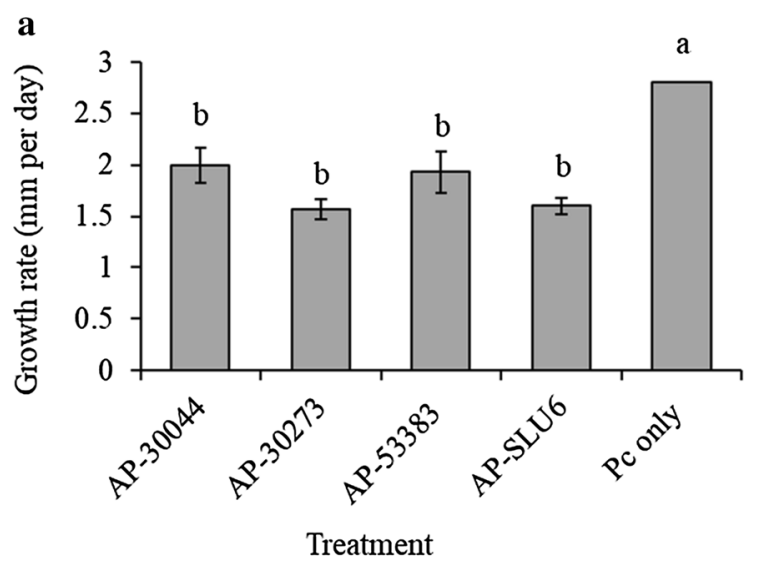

b

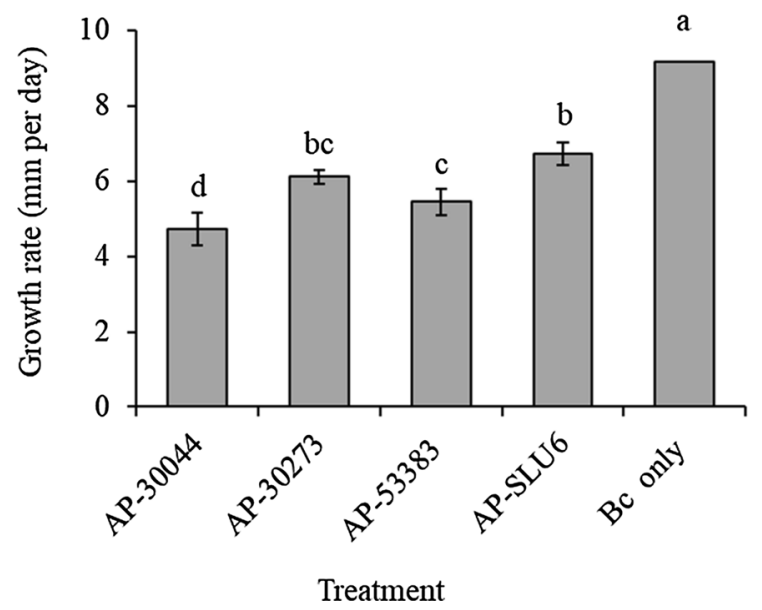

Fig. 1 Antagonism test of Aureobasidium pullulans strains (AP-30044, AP-30273, AP-53383 and AP-SLU6) against Phytophthora cactorum and Botrytis cinerea on potato dextrose agar (PDA) plates. a Growth rate of $P$. cactorum and $\mathbf{b} B$. cinerea during interaction with $A$. pullulans strains. Error bars indicate SE of six biological replicates. Different letters indicate a statistically significant difference $(p<0.001)$ between treatments as determined by Fisher's least significant difference test. AP Aureobasidium pullulans, Bc Botrytis cinerea, Pc Phytophthora cactorum

(Fig. 1b; Supplementary Figure S1). However, $A$. pullulans strains and both pathogenic fungi $B$. cinerea, and $P$. cactorum had overgrown each other after seven and ten DPI, respectively.

\section{Detached leaf assay against $P$. cactorum}

The necrotic lesion size on strawberry leaves was significantly reduced $\left(\mathrm{F}_{4,25}=18.6 ; p<0.001\right)$ in

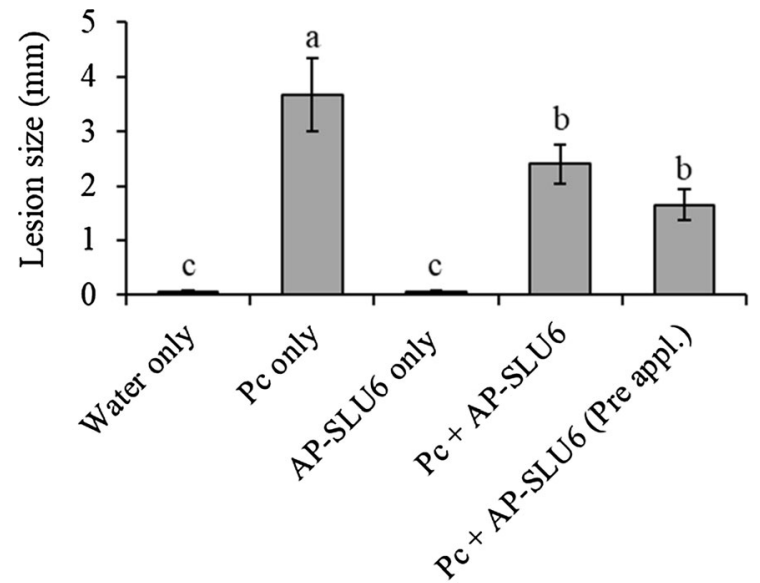

Treatment

Fig. 2 Antagonism test of Aureobasidium pullulans strain APSLU6 on detached strawberry leaves against crown rot disease. Error bars indicate SE of six biological replicates. Different letters indicate a statistically significant difference $(p<0.001)$ between treatments as determined by Fisher's least significant difference test. AP Aureobasidium pullulans, Pc Phytophthora cactorum

treatments where AP-SLU6 was applied either directly in combination with $P$. cactorum or as a pre-treatment compared with the control treatment in which only $P$. cactorum was applied (Fig. 2). However, pre-application of AP-SLU6 produced a more pronounced antagonistic effect against $P$. cactorum, which suggests that $A$. pullulans had enough time to colonize the surface of the leaves. No lesions were observed when AP-SLU6 was applied alone, while hardly any lesions developed in the control water treatment (Fig. 2). This is further evidenced by the trypan blue staining of the leaves where the reduced necrotic lesions were visualized after AP-SLU6 treatment, as shown in Fig. 3.

\section{Detached fruit assay against $B$. cinerea}

B. cinerea on fruits showed significantly $\left(\chi_{3}^{2}=25.15\right.$; $p<0.001)$ reduced disease severity when the APSLU6 strain conidial suspension was applied in direct combination with B. cinerea inoculum (Fig. 4). Likewise, disease severity was significantly reduced on fruits pre-treated with the AP-SLU6 strain followed by $B$. cinerea compared with the treatment where only $B$. cinerea was applied, i.e. the control (Fig. 4). No 


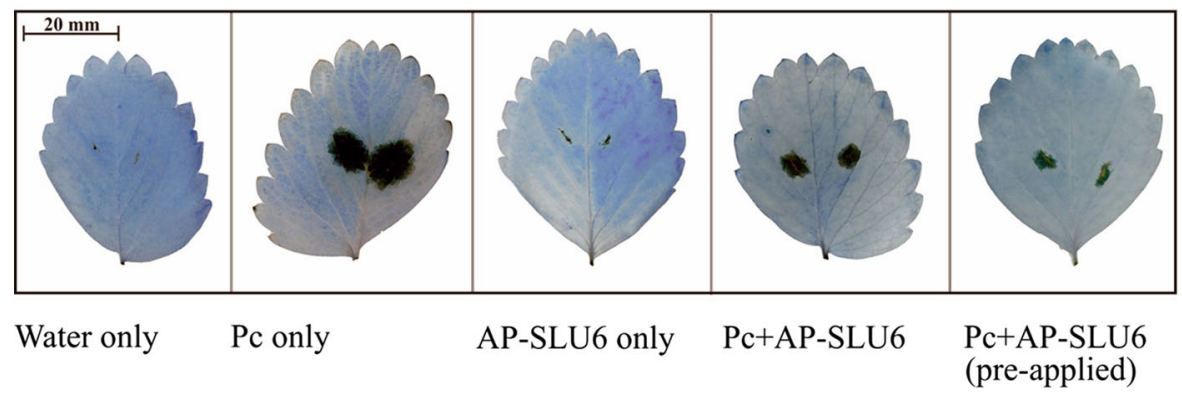

Fig. 3 Trypan blue staining of detached strawberry leaves during antagonism test of Aureobasidium pullulans strain APSLU6 against crown rot disease. Necrotic lesion sizes were

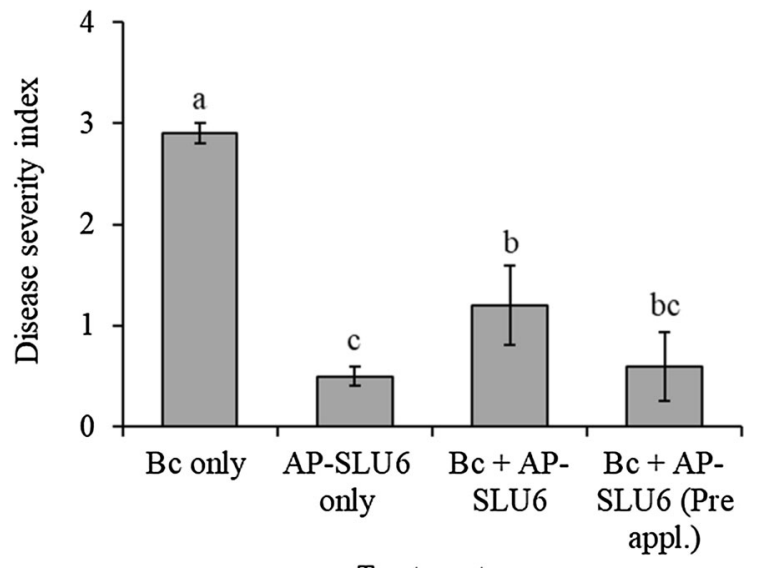

Treatment

Fig. 4 Antagonism test of Aureobasidium pullulans strain APSLU6 on detached strawberry fruits against grey mould disease. Error bars indicate SE of ten biological replicates. Different letters indicate a statistically significant difference $(p<0.05)$ between treatments as determined by Dunn's test with Bonferroni correction. AP Aureobasidium pullulans, Bc Botrytis cinerea

significant difference in symptom development was found between fruits pre-treated with AP-SLU6 followed by $B$. cinerea as compared to when APSLU6 was applied alone (Fig. 4).

Biocontrol of root rot disease

Application of AP-SLU6 significantly $\left(\chi_{4}^{2}=22.27\right.$; $p<0.001$ ) reduced the severity (approximately $73 \%$ ) of root rot disease compared with the control treatment where only $P$. cactorum was applied (Fig. 5). Likewise, application of AP-SLU6 in combination with $P$. cactorum reduced the disease severity (37\%). recorded using an Epson perfection V750 pro scanner. AP Aureobasidium pullulans, Pc Phytophthora cactorum

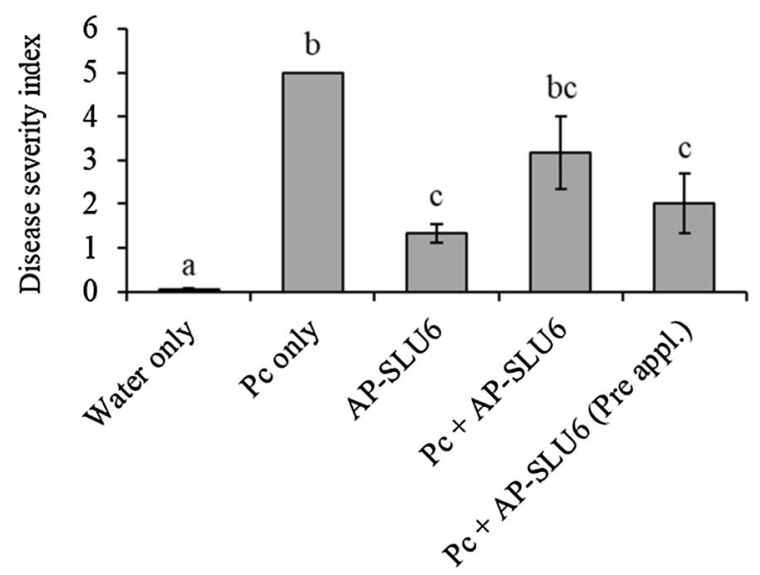

Treatment

Fig. 5 In vivo bioassay to test the biocontrol efficacy of Aureobasidium pullulans strain AP-SLU6 against root rot disease on strawberry. Error bars indicate SE of six biological replicates. Different letters indicate a statistically significant difference $(p<0.05)$ between treatments as determined by Dunn's test with Bonferroni correction. AP Aureobasidium pullulans, Pc Phytophthora cactorum

However, this reduction was not statistically significant. Similarly, significantly enhanced biocontrol efficacy was observed compared with the control treatment when AP-SLU6 was applied before $P$. cactorum (Fig. 5).

\section{Biocontrol of grey mould}

Spray application of AP-SLU6 to intact plants in any form, directly combined or in a pre-treatment application followed by $B$. cinerea, reduced the disease severity of grey mould on fruits compared with the control treatment (Supplementary Figure S2). 
However, this reduction was not statistically significant $\left(\chi_{4}^{2}=6.84 ; p=0.144\right)$.

\section{Discussion}

The current study was designed to investigate the biocontrol potential of $A$. pullulans against two important strawberry pathogens, i.e., P. cactorum and $B$. cinerea. Importantly, this is the first time that $A$. pullulans has been tested against the pathogen $P$. cactorum. The results are promising, showing that $A$. pullulans has potential to inhibit both of these pathogens, possibly reducing the need for synthetic fungicides in strawberry production.

The reduced growth rate of $P$. cactorum and $B$. cinerea during confrontation with A. pullulans strains compared with the control suggests that the biocontrol fungus A. pullulans has an inhibitory effect on the growth of the pathogenic oomycete/fungi. The mechanism behind the observed inhibitory impact on the growth of $P$. cactorum and $B$. cinerea remains unknown. However, it could be that $A$. pullulans produces antifungal compounds, proteases or enzymes or secretes volatile compounds that inhibit the pathogens. Previously, it has been shown that $A$. pullulans produces a broad range of extracellular enzymes (Molnárová et al. 2014) and antifungal peptides, for instance, aurebasidin A (Takesako et al. 1991). It has also been reported that A. pullulans is involved in degrading $B$. cinerea cell walls by secreting chitinase and protease in potato (Chen et al. 2018). Gostinčar et al. (2014) showed that different strains of A. pullulans vary considerably in their production of extracellular enzymes and sugar transporters. They suggested that these major differences between strains reflect ecological or evolutionary adaptations to their respective environment. Thus, strains isolated from different plants or other biotic or abiotic substrates may have very different lifestyles, and differ in their suitability for biocontrol use. Hence, we included several strains in our initial assays and studied the antagonistic activity of A. pullulans on both strawberry fruits and leaves. Our results revealed similar patterns in reducing necrotic lesions of $P$. cactorum on leaves and growth of $B$. cinerea on strawberry fruits when inoculation of pathogens was performed together with the biocontrol fungus APSLU6, either on leaves or fruit. However, pre- application of AP-SLU6 resulted in higher antagonism against $P$. cactorum, which could be explained by $A$. pullulans having enough time to colonize the surface of leaves and thus deliver greater protection against the development of necrotic lesions in the detached leaf assay. Previously, Adikaram et al. (2002) also showed that pre-treatment application of A. pullulans suppressed the growth of grey mould more efficiently on wound sites of green fruits of strawberries.

Our in vivo bioassay showed that AP-SLU6 is effective in controlling root rot disease of strawberry. It has previously been shown that A. pullulans can produce a compound called pullulan as well as polysaccharides which improve biofilm formation and are therefore helpful in the adhesion mechanism, thus explaining the increased level of antagonism and biocontrol efficacy against $P$. cactorum during in vitro or in vivo bioassays (Bozoudi and Tsaltas 2018; Freimoser et al. 2019).

Unexpectedly, our experiment to investigate the ability of $A$. pullulans to control grey mould under greenhouse conditions revealed no significant differences between the different treatments. However, application of AP-SLU6 alone or in combination with $B$. cinerea delayed the development of the disease on plants. The fact that our results on biological control of grey mould are in contrast with the observed in vitro antagonism might not be surprising given the complexity of biological control mechanisms, including not only competition for nutrients and space, but also antibiosis and direct or indirect parasitism via induction of plant defence reactions (Harman et al. 2004; Iqbal et al. 2020; Jensen et al. 2017). Another reason could be that poor colonization of A. pullulans on the fruit surface made it unable to cope with the high pathogenicity of $B$. cinerea. It has previously been shown that $A$. pullulans has the potential to control grey mould on strawberry and rotting of cherries, grapes and kiwi fruit (Ippolito et al. 1997; Schena et al. 1999). According to Jersch et al. (1989), reduction in the disease was attributed to quiescent pathogens and the presence of green fruits ( $c v$. Senga Sengana). An extract of green fruits contains an antifungal compound called proanthocyanidin and its higher concentration in the receptacle reduces colonization of $B$. cinerea, which is involved in controlling grey mould. Recently, Di Francesco et al. (2020) showed that $A$. pullulans plays an important role in reducing the disease incidence of grey mould in tomato in vivo. 
Surprisingly, our results showed grey mould symptoms on plants treated with only water. This could be explained by the dispersal mechanism of the $B$. cinerea, which is possibly spread through the air and via water splashes.

In summary, this study showed that $A$. pullulans is capable of reducing the severity of crown rot, root rot and grey mould in strawberry. This approach is probably a more environmentally and evolutionarily sustainable way to control these diseases than chemically based fungicides. The results are important because biocontrol is a cornerstone in Integrated Pest Management which in turn is globally endorsed as the future paradigm of crop protection (Stenberg 2017). However, more investigations are required to test commercially important parameters such as yield, fruit quality and as well as the mechanisms involved in order to understand the exact role of the biocontrol fungus A. pullulans and to improve biocontrol efficacy against the strawberry diseases.

Acknowledgements The authors thank the Swedish Research Council for Environment, Agricultural Sciences and Spatial Planning (FORMAS) (grant number 2016-00223; 2019-01316) and the Swedish Research Council (grant number 2019-04270) for financial support for this study.

Author contributions MI, MJ, RRV, EA and JAS conceived and designed the experiments. MJ performed the experiments. MI and MJ analysed the data. MAZ performed the trypan blue staining of strawberry leaves. MI and MJ wrote the manuscript with critical input from all authors. All authors read and approved the manuscript.

Funding Open access funding provided by Swedish University of Agricultural Sciences. This work was supported by the Swedish Research Council for Environment, Agricultural Sciences and Spatial Planning (FORMAS) (grant number 2016-00223; 2019-01316) and the Swedish Research Council (grant number 2019-04270).

Data availability All data generated or analysed during this study are included in this manuscript.

\section{Compliance with ethical standards}

Conflict of interest The authors declare that they have no conflict of interest related to funding or otherwise.

Ethical approval As no human or mammalian subjects were involved in this research, no ethical approval was required.

Consent for publication All authors consent to publication.
Open Access This article is licensed under a Creative Commons Attribution 4.0 International License, which permits use, sharing, adaptation, distribution and reproduction in any medium or format, as long as you give appropriate credit to the original author(s) and the source, provide a link to the Creative Commons licence, and indicate if changes were made. The images or other third party material in this article are included in the article's Creative Commons licence, unless indicated otherwise in a credit line to the material. If material is not included in the article's Creative Commons licence and your intended use is not permitted by statutory regulation or exceeds the permitted use, you will need to obtain permission directly from the copyright holder. To view a copy of this licence, visit http://creativecommons.org/licenses/by/4.0/.

\section{References}

Adikaram NK, Joyce DC, Terryc LA (2002) Biocontrol activity and induced resistance as a possible mode of action for Aureobasidium pullulans against grey mould of strawberry fruit. Australas Plant Pathol 31:223-229

Bozoudi D, Tsaltas D (2018) The multiple and versatile roles of Aureobasidium pullulans in the vitivinicultural sector. Fermentation 4:85

Bristow P, McNicol R, Williamson B (1986) Infection of strawberry flowers by Botrytis cinerea and its relevance to grey mould development. Ann Appl Biol 109:545-554

Chen P-H, Chen R-Y, Chou J-Y (2018) Screening and evaluation of yeast antagonists for biological control of Botrytis cinerea on strawberry fruits. Mycobiology 46:33-46

Di Francesco A, Mari M (2014) Use of biocontrol agents in combination with physical and chemical treatments: efficacy assessment. Stewart Postharvest Rev 1:2

Di Francesco A, Milella F, Mari M, Roberti R (2017) A preliminary investigation into Aureobasidium pullulans as a potential biocontrol agent against Phytophthora infestans of tomato. Biol Control 114:144-149

Di Francesco A, Calassanzio M, Ratti C, Mari M, Folchi A, Baraldi E (2018) Molecular characterization of the two postharvest biological control agents Aureobasidium pullulans L1 and L8. Biol Control 123:53-59

Di Francesco A, Di Foggia M, Baraldi E (2020) Aureobasidium pullulans volatile organic compounds as alternative postharvest method to control brown rot of stone fruits. Food Microbiol 87:103395

Dianez F, Santos M, Blanco R, Tello J (2002) Fungicide resistance in Botrytis cinerea isolates from strawberry crops in Huelva (southwestern Spain). Phytoparasitica 30:529

Ellis M, Wilcox W, Madden L (1998) Efficacy of metalaxyl, fosetyl-aluminum, and straw mulch for control of strawberry leather rot caused by Phytophthora cactorum. Plant Dis 82:329-332

Freimoser FM, Rueda-Mejia MP, Tilocca B, Migheli Q (2019) Biocontrol yeasts: mechanisms and applications. World J Microbiol Biotechnol 35:154

Garrido C, Carbú M, Fernández-Acero FJ, González-Rodríguez VE, Cantoral JM (2011) New insights in the study of 
strawberry fungal pathogens. Genes Genomes Genom 5:24-39

Golzar H, Phillips D, Mack S (2007) Occurrence of strawberry root and crown rot in Western Australia. Australas Plant Dis Notes 2:145-147

Gostinčar C, Ohm RA, Kogej T, Sonjak S, Turk M, Zajc J, Zalar P, Grube M, Sun H, Han J, Sharma A, Chiniquy J, Ngan CY, Lipzen A, Barry K, Grigoriev IV, Gunde-Cimerman N (2014) Genome sequencing of four Aureobasidium pullulans varieties: biotechnological potential, stress tolerance, and description of new species. BMC Genom 15:549

Harman GE, Howell CR, Viterbo A, Chet I, Lorito M (2004) Trichoderma species-opportunistic, avirulent plant symbionts. Nat Rev Microbiol 2:43-56

Ippolito A, Nigro F, Romanazzi G, Campanella V (1997) Field application of Aureobasidium pullulans against Botrytis storage rot of strawberry. In: Non conventional methods for the control of post-harvest disease and microbiological spoilage. Workshop proceedings COST, pp 127-133

Iqbal M, Dubey M, McEwan K, Menzel U, Franko MA, Viketoft M, Jensen DF, Karlsson M (2018) Evaluation of Clonostachys rosea for control of plant-parasitic nematodes in soil and in roots of carrot and wheat. Phytopathology 108:52-59

Iqbal M, Dubey M, Broberg A, Viketoft M, Jensen DF, Karlsson M (2019) Deletion of the nonribosomal peptide synthetase gene nps 1 in the fungus Clonostachys rosea attenuates antagonism and biocontrol of plant pathogenic Fusarium and nematodes. Phytopathology 109:1698-1709

Iqbal M, Broberg M, Haarith D, Broberg A, Bushley KE, Durling MB, Viketoft M, Jensen DF, Dubey M, Karlsson M (2020) Natural variation of root lesion nematode antagonism in the biocontrol fungus Clonostachys rosea and identification of biocontrol factors through genome-wide association mapping. Evol Appl 13:2264-2283

Janisiewicz W, Tworkoski T, Sharer C (2000) Characterizing the mechanism of biological control of postharvest diseases on fruits with a simple method to study competition for nutrients. Phytopathology 90:1196-1200

Jarvis WR (1977) Botryotinia and Botrytis species: taxonomy, physiology and pathogenicity: a guide to the literature. Monograph No. 15. Research Branch, Canada Department of Agriculture, Harrow, Ontario, Canada

Jensen D, Karlsson M, Lindahl B (2017) Fungal-fungal interactions: from natural ecosystems to managed plant production with emphasis on biological control of plant diseases. In: Gighton J, White JF (eds) The fungal community: its organization and role in the ecosystem. CRC Press, Taylor \& Francis Group, Oxford, pp 549-562

Jersch S, Scherer C, Huth G, Schlösser E (1989) Proanthocyanidins as basis for quiescence of Botrytis cinerea in immature strawberry fruits/Proanthocyanidine als Ursache der Quieszenz von Botrytis cinerea in unreifen Erdbeerfrüchten. Zeitschrift für Pflanzenkrankheiten und Pflanzenschutz. J Plant Dis Prot 96:365-378

Klein MN, Kupper KC (2018) Biofilm production by Aureobasidium pullulans improves biocontrol against sour rot in citrus. Food Microbiol 69:1-10

Kovach J, Petzoldt R, Harman GE (2000) Use of honey bees and bumble bees to disseminate Trichoderma harzianum
1295-22 to strawberries for Botrytis control. Biol Control 18:235-242

Madhupani Y, Adikaram N (2017) Delayed incidence of stemend rot and enhanced defences in Aureobasidium pullulans-treated avocado (Persea americana Mill.) fruit. J Plant Dis Prot 124:227-234

Mari M, Martini C, Spadoni A, Rouissi W, Bertolini P (2012) Biocontrol of apple postharvest decay by Aureobasidium pullulans. Postharvest Biol Technol 73:56-62

Molnárová J, Vadkertiová R, Stratilová E (2014) Extracellular enzymatic activities and physiological profiles of yeasts colonizing fruit trees. J Basic Microbiol 54:S74-S84

Munir M, Iqbal S, Baloch J, Khakwani A (2015) In vitro explant sterilization and bud initiation studies of four strawberry cultivars. J Appl Hortic 17:192-198

Myresiotis C, Karaoglanidis G, Tzavella-Klonari K (2007) Resistance of Botrytis cinerea isolates from vegetable crops to anilinopyrimidine, phenylpyrrole, hydroxyanilide, benzimidazole, and dicarboximide fungicides. Plant Dis 91:407-413

Nellist CF, Vickerstaff RJ, Sobczyk MK, Marina-Montes C, Wilson FM, Simpson DW, Whitehouse AB, Harrison RJ (2019) Quantitative trait loci controlling Phytophthora cactorum resistance in the cultivated octoploid strawberry (Fragaria $\times$ ananassa). Hortic Res 6:60

Parafati L, Vitale A, Restuccia C, Cirvilleri G (2015) Biocontrol ability and action mechanism of food-isolated yeast strains against Botrytis cinerea causing post-harvest bunch rot of table grape. Food Microbiol 47:85-92

Parafati L, Vitale A, Restuccia C, Cirvilleri G (2017) Performance evaluation of volatile organic compounds by antagonistic yeasts immobilized on hydrogel spheres against gray, green and blue postharvest decays. Food Microbiol 63:191-198

Petrasch S, Knapp SJ, Van Kan JA, Blanco-Ulate B (2019) Grey mould of strawberry, a devastating disease caused by the ubiquitous necrotrophic fungal pathogen Botrytis cinerea. Mol Plant Pathol 20:877-892

Porras M, Barrau C, Arroyo F, Santos B, Blanco C, Romero F (2007) Reduction of Phytophthora cactorum in strawberry fields by Trichoderma spp. and soil solarization. Plant Dis 91:142-146

Rabølle M, Spliid NH, Kristensen K, Kudsk P (2006) Determination of fungicide residues in field-grown strawberries following different fungicide strategies against gray mold (Botrytis cinerea). J Agric Food Chem 54:900-908

Ries, S.M. (1995) RPD No. 704-Gray mold of strawberry. Available at http://ipm.illinois.edu/diseases/series700/ rpd704/. Accessed 13 Oct 2020

Schena L, Ippolito A, Zahavi T, Cohen L, Nigro F, Droby S (1999) Genetic diversity and biocontrol activity of Aureobasidium pullulans isolates against postharvest rots. Postharvest Biol Technol 17:189-199

Stenberg JA (2017) A conceptual framework for integrated pest management. Trends Plant Sci 22:759-769

Stensvand A, Herrero M, Talg $\varnothing$ V (1999) Crown rot caused by Phytophthora cactorum in Norwegian strawberry production. EPPO Bull 29:155-158

Takesako K, Ikai K, Haruna F, Endo M, Shimanaka K, Sono E, Nakamura T, Kato I (1991) Aureobasidins, new antifungal 
antibiotics taxonomy, fermentation, isolation, and properties. J Antibiot 44:919-924

Toljamo A, Blande D, Kärenlampi S, Kokko H (2016) Reprogramming of strawberry (Fragaria vesca) root transcriptome in response to Phytophthora cactorum. PLoS ONE 11(8):e0161078

van Wees S (2008) Phenotypic analysis of Arabidopsis mutants: trypan blue stain for fungi, oomycetes, and dead plant cells. Cold Spring Harb Protoc pdb. prot4982

Yourman L, Jeffers S (1999) Resistance to benzimidazole and dicarboximide fungicides in greenhouse isolates of Botrytis cinerea. Plant Dis 83:569-575

Zhang D, Spadaro D, Garibaldi A, Gullino ML (2010) Efficacy of the antagonist Aureobasidium pullulans PL5 against postharvest pathogens of peach, apple and plum and its modes of action. Biol Control 54:172-180

Mudassir Iqbal is a post-doctoral researcher at the Swedish University of Agricultural Sciences. His research is mainly focused on fungal-fungal and fungal-nematode interactions in relation to plant pathology and biological disease control.

Maha Jamshaid obtained the joint Master degree in plant health in sustainable cropping systems as an Erasmus scholar. Her research, which is part of this paper, focused on biocontrol of fungal diseases.
Muhammad Awais Zahid is a PhD student at the Swedish University of Agricultural Sciences. His main research focuses on understanding plant immunity in potato and its interaction with Phytophthora infestans.

Erik Andreasson is a professor of plant protection at the Swedish University of Agricultural Sciences and leader of the resistance biology unit. His main research focuses on new and combinatory resistance mechanisms in plants.

Ramesh Vetukuri is an associate professor at the Swedish University of Agricultural Sciences. He studies plant-pathogenbiocontrol interactions to develop new and sustainable ways of disease control. His recent focus is on controlling plant diseases via small RNAs, an emerging field that emphasises the role of small RNA trafficking.

Johan A. Stenberg is a professor of integrated plant protection at the Swedish University of Agricultural Sciences and director of the SLU Center for Biological Control. His main research focuses on synergistic optimization of biocontrol and plant resistance within the framework of integrated pest management (IPM). 